Rico, C. (2020) La contabilidad en Colombia de la segunda mitad del siglo XIX: representaciones desde la literatura de los cuadros de costumbres. Contaduría Universidad de Antioquia, 76, 115-134.

Doi: https://doi.org/10.17533/udea.rc.n76a05

\title{
La contabilidad en Colombia de la segunda mitad del siglo XIX: representaciones desde la literatura de los cuadros de costumbres
}

Carlos Orlando Rico Bonilla carlosricob@usantotomas.edu.co

Universidad Santo Tomás Orcid: 0000-0002-0060-0431 
La contabilidad en Colombia de la segunda mitad del siglo XIX: representaciones desde la literatura de los cuadros de costumbres

Resumen: Este estudio es una investigación histórica sobre las representaciones de la contabilidad en Colombia, durante la segunda mitad del siglo XIX, a partir de un análisis documental e interpretativo, que tiene por fuentes primarias textos literarios de la época, especialmente, los cuadros de costumbres y la correspondencia del comerciante Ricardo Silva Frade. Al respecto, se encuentran dos perspectivas: la contabilidad como una herramienta útil para la administración racional de los negocios en el marco de un contexto político y económico de incertidumbre y transición a instituciones y valores éticos de corte capitalista y, además, como un elemento probatorio de la legalidad y la honradez del comerciante en el desarrollo de las actividades mercantiles, de cara a la administración estatal, los clientes, los prestamistas y los acreedores.

Palabras clave: Colombia, Contabilidad, Historia de la contabilidad, Cuadros de costumbres, Ricardo Silva Frade.

Accounting in Colombia in the second half of the XIX century: representations of custom frameworks from the literature

Abstract: This study is a historical research on the representations of accounting in Colombia during the second half of the XIX Century, from a documentary and interpretive analysis using literary texts of the period as primary sources, especially custom frameworks and the correspondence of the merchant Ricardo Silva Frade. In this respect, two perspectives are found: accounting as a useful tool for the rational management of the businesses in the framework of a political and economic context of uncertainty and transition towards institutions and ethical values of capitalist type; and as a probative element of the legality and honesty of the merchant in the development of the mercantile activities, in front of state administration, customers, lenders and creditors.

Keywords: Colombia, Accounting, Accounting history, Custom frameworks, Ricardo Silva Frade.

A contabilidade na Colômbia da segunda metade do século XIX: Representações desde a literatura dos quadros de costumes

Resumo: Este estudo é uma pesquisa histórica sobre as representações da contabilidade na Colômbia, durante a segunda metade do século XIX, a partir de uma análise documental e interpretativa, que tem por fontes primárias textos literarios da época, especialmente, os quadros de costumes e a correspondência do comerciante Ricardo Silva Frade. Respeito deste assunto, encontram-se duas perspetivas: a contabilidade como uma ferrramenta útil para a administração racional dos negócios no marco de um contexto político e económico de incerteza e transição a instituições e valores éticos de tipo capitalista e, além disso, como um elemento probatório da legalidade e a honradez do comerciante no desenvolvimento das atividades mercantis, de fronte para a administração estatal, os clientes, os prestamistas e aos credores.

Palavras- chave: Colômbia, Contabilidade, História da Contabilidade, Quadros de Costumes, Ricardo Silva Frade

La comptabilité en Colombie pendant la seconde moitié du XIX siècle : des représentations des tableaux de costumes à partir de la littérature

Résumé: cette étude est une recherche historique sur les représentations de la comptabilité en Colombie pendant la seconde moitié du XIX siècle, à partir d'une analyse documentaire ainsi qu' interprétative, qui a pour sources primaires des textes littéraires de l'époque, en particulier les tableaux de coutumes et les courriers dappartenant au commerçant Ricardo Silva Frade. À ce rapport, deux perspectives ont été proposées : d'une part, la comptabilité en tant qu'outils utils pour l'administration rationale des affaires dans un contexte politique et économique d'incertitude et de transition vers des institutions et des valeurs étiques d'une touche capitaliste. D'autre part, en tant qu'élément probatoire de la légalité et de l'honnêteté du commercant dans le développement des activitiés commerciales face à l'administration de l'État, aux clients, aux créanciers et aux garants. Mots-clés: Colombie, comptabilité, histoire de la comptabilité, tableux de coutumes, Ricardo Silva Frade 


\title{
La contabilidad en Colombia de la segunda mitad del siglo XIX: representaciones desde la literatura de los cuadros de costumbres
}

\author{
Carlos Orlando Rico Bonilla \\ https://doi.org/10.17533/udea.rc.n76a05 \\ Primera versión recibida en enero de 2020 - Versión aceptada en marzo de 2020
}

\section{Introducción}

I a presente investigación histórica tiene por objeto el estudio de las Lrepresentaciones de la contabilidad en Colombia, durante la segunda mitad del siglo XIX. Esto primordialmente bajo dos perspectivas: primero, como una herramienta de gestión racional de los negocios en un contexto de incertidumbre en el cual el país hacía un lento tránsito a instituciones y valores éticos capitalistas y, segundo, como un soporte probatorio de la legalidad y la honradez del comerciante en el desarrollo de sus actividades mercantiles.

En este sentido, el concepto de representación hace referencia a construcciones psicológicas y sociológicas con las que se interpreta y comprende la interacción de las personas y las comunidades con su entorno cultural particular. Se busca estudiar y reflexionar sobre el pasado, en este caso, sobre las diversas imágenes de diferentes realidades históricas respecto de las prácticas e ideas contables (Machado, 2006, 2011).

En esta investigación se ha tratado de extender el enfoque, examinando como fuentes primarias textos literarios y correspondencia privada de la época, aunque estas no son las bases convencionales de los estudios de historia de la contabilidad, en los que prevalece la observación de los libros de cuentas, la legislación comercial y los actos administrativos gubernamentales. Además, considerando que:

Las preguntas a la historia de Colombia no son preguntas que formula un historiador profesional, sino preguntas que plantea el análisis de la literatura, que no se reduce a la literatura como expresión estética, sino como vasta expresión de las maneras de pensar y actuar de los estratos sociales que la han cultivado. (Gutiérrez, 2000, p.10) 
Rico, C. La contabilidad en Colombia de la segunda mitad del siglo XIX...

En términos metodológicos, se establece como enfoque general de análisis un enfoque documental e interpretativo; esto es, un ejercicio de identificación y examen de fuentes primarias que son contextualizadas en el entorno político y económico respectivo, para deducir de allí indicios y conceptos sobre los cuales estructurar un relato histórico de las representaciones contables correspondientes (Hernández, 2013; Rico, 2018).

Por tanto, el documento se estructura de la siguiente manera: además de esta introducción, en la segunda sección se describen los aspectos metodológicos. En la tercera se reseñan algunos aspectos contables derivados del entorno del país en el periodo indagado. En la cuarta y quinta parte se indican y describen elementos de caracterización de las perspectivas de representación. Finalmente, en el sexto apartado, se formulan las conclusiones.

\section{Aspectos metodológicos}

Es relevante mencionar que, dada la naturaleza histórica del presente estudio, este se ha planteado con un carácter cualitativo, sustentado en un enfoque interpretativo que para su desarrollo se centró en la técnica de la revisión bibliográfica y el respectivo análisis de contenidos. Por esta razón, igualmente, se sigue una serie de fases que se describen a continuación:

En primer lugar, se buscó identificar varias fuentes primarias potenciales, consultado en los catálogos de dos bibliotecas públicas que conservan una gran cantidad de patrimonio documental nacional: la Biblioteca Luis Ángel Arango y la Biblioteca Nacional de Colombia, a partir de las palabras claves: contabilidad, teneduría de libros, cuentas, literatura y siglo XIX, y teniendo como referencia, además, algunos estudios sobre la historia literaria colombiana, por ejemplo, Gómez (1946), Williams (1991) y Beckman (2009).

También se exploró en un conjunto de investigaciones previas, como las de Mattessich (2000), Grajales (2007), Czarniawska (2008) y Pérez (2008), que han indagado y ejemplificado de qué manera en la disciplina contable se ha analizado y problematizado la singular manifestación de la contabilidad, su significado y la observación de sus prácticas en diferentes narraciones literarias, ambientadas en diversos lugares y tiempos.

En segundo lugar, en el marco de una no muy numerosa cantidad de textos literarios se reconoció en los cuadros y escenas de costumbres, un área en la que era posible encontrar y evidenciar algunas descripciones y referencias a las prácticas e ideas contables de la época. Además, esta literatura en prosa que pretendía retratar y resaltar tradiciones y valores populares, tenía por autores a personalidades del mundo de la élite de los negocios y la política decimonónica, que claramente tenían cierta educación en estas cuestiones, y también en aspectos de derecho y economía política (Gordillo, 2003). 
Este es el caso del ilustre comerciante bogotano Ricardo Silva Frade (18361887), quien, junto con su hijo, el célebre poeta José Asunción Silva (1865-1896) ha sido objeto de bastantes estudios en los que se mencionan reiteradamente algunos detalles del manejo contable que daban a sus actividades mercantiles, particularmente a su casa comercial "R. Silva e Hijo" (cuya publicidad se puede apreciar en el anexo 1), y a las finanzas de su familia (Pérez, 2008; Santos, 1992; Vallejo, 1995; Rico, 2018).

Con esta información, en tercer lugar, se procedió a examinar los textos seleccionados en el marco de los parámetros históricos correspondientes al entorno político, económico y contable de la segunda mitad del siglo XIX, que se delimita en el siguiente apartado, para establecer algunas de las temáticas contables más recurrentes y la manera en la que se describían y comentaban en los pasajes literarios. Todo esto para, finalmente, definir, estructurar y caracterizar las representaciones que se argumentan posteriormente.

\section{El contexto político-económico y contable de Colombia en la segunda mitad del siglo XIX}

En la dimensión política, el periodo de la historia nacional examinado se caracterizó, principalmente, por el cambio de un esquema administrativo federal apoyado en ideologías de tendencias liberales y utilitaristas (1850-1885) que estaban impulsadas, entre otras razones, por un ideal de ruptura con las instituciones y las relaciones de producción y subordinación heredadas de la colonia española, hacia una propuesta doctrinal que instituyó un enfoque organicista y centralista del Estado, apoyado en directrices conservadoras y católicas (1886-1930).

La carta constitucional de 1863 fue la expresión de la primera opción, que contemplaba un Estado más secular, promotor del libre cambio, una mayor oferta educativa pública y una más profunda descentralización de la función y misionalidad gubernamental, así como de la recaudación de los tributos y de otras rentas públicas. Le sucedió en 1886 el proyecto proteccionista de la Regeneración, que devolvió a la iglesia católica el liderazgo en los temas de enseñanza e instrucción y centralizó el poder político en el gobierno capitalino y la figura del presidente de la república.

Las tensiones entre una y otra tendencia política, que en últimas eran el resultado de los conflictos por el poder entre los estamentos dominantes de la sociedad colombiana, contribuyeron a aumentar las guerras civiles y el ambiente subyacente de desequilibrio que rigió en la mencionada centuria (Colmenares, 1968). Además, esto influyó en una perspectiva de menor crecimiento económico, especialmente desde la década de 1880, en un país de vocación agrícola que difícilmente pudo conectarse con los mercados internacionales $\mathrm{y}$, por ende, generar flujos de capital y crédito constantes que 
Rico, C. La contabilidad en Colombia de la segunda mitad del siglo XIX...

se lograran direccionar a inversiones productivas e infraestructura privada y pública de soporte (Kalmanovitz y López, 2010).

Al iniciar la segunda mitad del siglo XIX, la eliminación del estanco del tabaco, establecido desde la colonia española, permitió el florecimiento de una considerable cantidad de rentables negocios privados vinculados a la producción, la comercialización y la exportación de este bien de consumo, por ejemplo, la empresa de Montoya, Sáenz \& Compañía (Colmenares, 1968; Molina, 2003). De manera que el grupo de los comerciantes, que venía en ascenso desde la independencia del país, se benefició de este proceso no solo por los réditos de las breves bonanzas de las décadas de 1850 y 1870, sino además, porque para ejercer un adecuado control de los recursos fue necesario aplicar herramientas de gestión como la contabilidad por partida doble (Palacio, 1979; Rico, 2015). Ricardo Silva Frade (1879) sobre las prácticas contables de aquel entonces, comenta:

Puedo asegurarle que con tal cual honrosa excepción, como la Casa de Montoya, Sáenz \& Compañía, iniciadora de todo progreso comercial en el país, y que tenía escritorio y contabilidad en debida forma, los demás comerciantes se limitaban a llevar un simple libro de Cargo y Data, incompleto y deficiente, o se ajustaban a esta sencilla regla: "lo que tengo ahí está, y lo que falta me lo he comido", sobrando de consiguiente, los libros con puntas de cobre, los enredos escritos en ellos, y el trabajo de llevarlos para llegar en definitiva, a aquel mismo resultado práctico. (1879, pp.755756)

Este evento germinal, aún poco estudiado en la historia de la contabilidad colombiana, coincidió con dos cambios fundamentales en la exigua regulación contable local: en el escenario público, la materialización de la reforma de las finanzas gubernamentales de 1846, que estableció en la práctica a la partida doble como el parámetro base en la elaboración de las cuentas públicas y, en el escenario privado, la expedición del Código de Comercio de 1853, que entre otras cosas reforzó la obligación de llevar contabilidad por parte de los comerciantes (Rico, 2015; Sierra, 2001).

A lo largo de la segunda mitad del siglo XIX hubo otros dos aspectos que implicaron modificaciones sustanciales en la regulación, las ideas y las prácticas contables en Colombia. Primero, la definición legal y el desarrollo de las pioneras sociedades anónimas por medio de las cuales se fomentaron y constituyeron empresas bancarias, de seguros, ferrerías y ferrocarriles (Ariza, 2001; Means, 2010; Rico, 2012); esto significó un complemento en la determinación del patrimonio, los inventarios y la tesorería, que eran el eje de la teneduría de libros, con un enfoque administrativo dirigido también a establecer rentabilidades, costos de operación y financiación y reconocimiento de los activos fijos en estas industrias (Rico, 2016), pero además en otras, por ejemplo, las muy prometedoras de la quina y el café (Ocampo, 1984; Palacio, 
1979), que a pesar de su relevancia tampoco han sido analizadas desde la óptica histórico-contable.

En segundo lugar, una constante inestabilidad de la estructura monetaria del país, la cual se agravó con la emisión (legal y clandestina) de papel moneda por parte del Banco Nacional en 1886 y tocó fondo con la hiperinflación que durante la Guerra Civil de los Mil Días azotó al país entre 1899 y 1902. Desde la colonia, las autoridades gubernamentales habían tenido enormes dificultades para regular la circulación de una importante cantidad de monedas con diferentes denominaciones y calidades, elaboradas en bronce, níquel o plata. Sobre este último metal, muy escaso en el país, se realizaban la gran mayoría de las transacciones ordinarias en el mercado interno, mientras en un proceso desbalanceado, las importaciones y exportaciones se adelantaban sobre el patrón oro (Ocampo, 1994). Como en 1886 le comentaba José Asunción Silva a su padre, sobre la marcha del negocio familiar mientras él se encontraba de viaje de negocios por Europa:

La mala situación del papel moneda se marca de día en día. Hoy vale con el 1 y medio al 2 por moneda de 0.500 . Hay ya $5 \%$ de diferencia entre esta y la de 0.835 . Esta baja de la moneda nueva estando nosotros comprometidos en todas nuestras obligaciones por 0.835 me hará hacer toda especie de esfuerzo para realizar, sobre todo la mercancía vieja que nos representa un aumento en la deuda, al cual es preferible la disminución de la ganancia, para hacernos a nuestro dinero antes de que la depreciación de las nuevas emisiones se haga más sensible. (1996, p. 11)

Particularmente, esta situación que dificultaba el progreso y la solvencia de las actividades mercantiles y tenía un impacto sobre la toma de decisiones en la gestión y la financiación de los negocios, incidió en la manera en que se percibía, entendía y representaba a la contabilidad, tema de los siguientes apartados.

\section{Saber intrincado pero útil para el comercio}

La mencionada inestabilidad monetaria tuvo dos implicaciones relevantes sobre los aspectos contables: se hizo complejo el manejo de la unidad de cuenta, es decir, la moneda de referencia legal en la contabilidad oficial y mercantil que sirve para regular y fijar los precios (Quijano, 1908) y, también, se deterioró la cantidad y calidad de los medios de pago en la economía, un aspecto central en el rol que tiene la contabilidad como un instrumento de medición y conciliación de los flujos monetarios (dinero) y los reales (mercancías) (González, 2010).

Respecto del primer asunto, es necesario tener en cuenta que los comerciantes colombianos, especialmente los dedicados a las exportaciones, llevaban sus libros considerando una paridad entre el oro y la plata, pero en 1871 cuando los precios internacionales de esta se desplomaron en medio de 
Rico, C. La contabilidad en Colombia de la segunda mitad del siglo XIX...

las crisis financieras en Europa Occidental y Estados Unidos, este supuesto ya no fue sostenible. Además, había que conciliar los valores registrados con el volátil y manipulado papel moneda (Ocampo, 1984; 1994; Rico, 2012).

En estos reprocesos de conversión de los datos, la elaboración de la contabilidad se hizo muy compleja y costosa con relación a los beneficios de información que reportaba para los propietarios de los negocios. En el estilo literario de Silva Frade, en su cuadro de costumbres Ponga usted tienda:

Mi libro diario me dice a cada paso de dónde proceden las fuertes sumas que debo, y me manifiesta que he dado al fiado las mercancías, y que éstas no me han sido pagadas; cosas que yo también sé hace mucho tiempo, y las páginas de mi "Mayor" guardan con religioso respeto los nombres de mis deudores, como guardan las losas de las tumbas los restos de los que fueron. (1883, p. 45)

Esto reforzaba la representación de la contabilidad como un saber intrincado, de difícil acceso y tedioso de aprender, que nada más era dominado por unos pocos ilustrados, que habían logrado entender confusas teorías extranjeras (Rico, 2018). La resistencia hacia el uso del método de la partida doble fue una constante a lo largo de aquella época, como lo ejemplifica la siguiente escena, entre un aprendiz de negocios y su tío mentor, en la novela de costumbres Entre Primos de Manuel Marroquín (1897):

Pablo, aunque espeluznado al ver tantos delitos de lesa contabilidad y de leso sentido común, no se atrevió a los principios a hacer otra cosa que escribir y callar. Días andando, se aventuró a hacerle a su tío algunas observaciones.

En cierta ocasión en que, por haberse embrollado desacostumbradamente una cuenta que era urgentísimo aclarar, se patentizó la perversidad del sistema adoptado por D. Leonardo, le dijo su sobrino:

-Si a usted no le pareciera mal, tal vez se podrían llevar estas cuentas de modo que en el momento que se ofreciera saber el estado de alguna...

- Hola! interrumpió el tío; ya me quieres venir con las modas y con esas sus partidas dobles. Esos son enredos que han inventado ahora para confundir a la gente.

- No, tío: no es eso precisamente, ni yo sería capaz de...

-Nada. Dejémonos de embolismos. Que caja a caja, y que caja a varios, y que varios a caja, y que varios a varios... ¿Quién diantre va a saber quiénes son esos varios?

-Si usted consintiera en que hiciéramos un ensayo...

-Nada, nada. Y luego aquello de las obligaciones por pagar y las obligaciones por cobrar, como si todas las obligaciones no fueran para cobrarlas y para pagarlas. Y el saldo, y el balance, y el demonio que te lleve si me vuelves con esos embelecos. (pp. 54-55) 
Por esta razón, igualmente, se observaba una creciente preocupación por lograr una mayor educación en temas contables, resaltando aspectos morales y técnicos asociados al mundo de los negocios. En este sentido, el principal objetivo de los libros de texto y los profesores de contabilidad de aquel entonces era simplificar y hacer más ameno el proceso de instrucción asociado (Rico, 2018). En concepto del referido comerciante Ricardo Silva Frade:

No hace muchos años que el estudio de la Teneduría de libros por el sistema de la partida doble era para la mayor parte de los comerciantes una verdadera empresa de romanos, y para los jóvenes un trabajo difícil y complicado por la oscuridad y palabrería inútil de rus reglas. La enseñanza de los grandes misterios de aquel arte pertenecía exclusivamente a dos o tres profesores teóricos que habían leído a Laporte o Blondel, y que se esforzaban inútilmente en hacer comprender a sus discípulos el sistema de los Médicis, sencillo en su origen y que, convertido luego en una algarabía tan detestable como estéril en sus resultados prácticos, inspiraba una aversión invencible a muchos de los ricos negociantes de aquella época. (1879, pp.755-756)

Respecto del segundo asunto, la escasez de numerario impactó negativamente los medios de pago, lo que también implicó un ajuste del entorno económico a un menor número de transacciones comerciales, la mayoría de las cuales se concentraba en la adquisición y el intercambio de bienes de consumo básicos (Ocampo, 1994). Esto limitó la expansión de los mercados de productos industriales y los de prestación de servicios profesionales, incluyendo el contable.

No se trata de que no hubiera personas que ofertaran y obtuvieran beneficios de las actividades contables; de hecho, fue en este periodo, por ejemplo, que se hizo visible la figura del revisor fiscal en los bancos y los ferrocarriles (Rico, 2012, 2016). También, en el Directorio General de Bogotá de Cupertino Salgado (1893) se halla que treinta hombres se identificaban como contabilistas dedicados a asesorías y a la prestación de servicios asociados. Además, en una particular descripción sobre la cotidianidad del comercio de la Provincia de Vélez, fruto de su peregrinación por el norte de la Nueva Granada, el político y educador liberal Manuel Ancízar (1853) señalaba:

Desde las tres en adelante comienza el movimiento de retirada de los expendedores y el arreglo de sus cuentas por préstamos recíprocos que se han hecho, el cual suele parar en desarreglo de palabras y obras, según la complicación de las cuentas o la cantidad de chicha que los contabilistas llevan dentro. (p. 91)

El asunto era que, dada la estrechez de la economía y, en general, su dependencia de las bonanzas de los productos agrícolas y mineros de exportación en los mercados internacionales, la mayoría de los comerciantes y otros empresarios no tenían los incentivos para contratar trabajos especializados como la teneduría de libros o la revisión de esta (Cubides, 1991); era preferible que un socio propietario o mayordomo llevara las cuentas y otros, si era posible, las examinaran y fenecieran, bajo la figura de una comisión inspectora. 
Rico, C. La contabilidad en Colombia de la segunda mitad del siglo XIX...

No obstante estos elementos restrictivos derivados del precario contexto político y económico, que limitaban el desarrollo de las prácticas de contabilidad en el país, la representación de esta para varios agentes económicos era el de una herramienta útil que soportaba la racionalidad en la toma de decisiones administrativas; un símbolo de los nuevos tiempos en la transformación ambivalente de una mentalidad anclada en los principios coloniales que hacía un tránsito lento a una guiada por valores capitalistas. En paralelo con la literatura, como lo reflejan los cuentos y poemas de los Silva y sus contemporáneos, se da la transición del costumbrismo (Ricardo) al modernismo (José Asunción) (Beckman, 2009; Gordillo, 2003; Santos, 1992). En otras palabras:

El comercio facilitó el ascenso social y fomentó un cambio de mentalidad que Ricardo Silva ilustró con intención humorística en un artículo de costumbres, Estilo del siglo, de 1860 , en el que presenta una carta de amor llena de vocablos, giros y una lista de regalos y cartas tomados del lenguaje de la contabilidad. Pero este cambio de mentalidad y la forma de ascenso social aristocratizante se enmarcaron en el ideal de la sociedad colonial. Esta superposición o, coexistencia de lo simultáneo con lo no simultáneo, como dice Ernst Bloch, propio de toda transición (Gutiérrez, 2000, p.12)

El mencionado cuadro se reproduce en el anexo 2; en él se puede apreciar la versatilidad del lenguaje contable y comercial y su aplicación simbólica en el marco de esta tendencia de transición. En otro interesante ejemplo, se advierte este cambio institucional y cultural en los objetos y las condiciones materiales de la sociedad, especialmente en los altos estamentos de esta, como se lee en el cuadro de Las llavecitas:

Sirva hoy de tema esta nueva arandela de la vida llamada las llavecitas, parte indispensable de los chismes de la actual casa de familia; diabólica invención compañera del crochet, de la frivolité, de los polvos de arroz a la violeta, de los monogramas, de los albums de estampillas, de las alzaderas, del polissoir, del cachenez, de los aquariums y de los demás elementos de felicidad, característicos del hogar moderno (...). (Silva, 1883, p. 145)

A lo largo de los diferentes cuadros de costumbres colombianos se encuentran una y otra vez reflexiones similares en las que se contrastaba la idea del progreso moderno con el olvido de las tradiciones previas (Gordillo, 2003), en el marco ideológico de vocablos contables y económicos. Por ejemplo:

El trabajo es la fuente de riqueza; trabajemos, pues, para ser ricos, porque el dinero trae consigo los placeres y las comodidades, así como la virtud nos da el respeto y las consideraciones (...). (Silva, 1883, p. 40)

(...) vino el progreso moderno que todo lo ha invadido llevándose de paso los rasgos característicos de nuestras sencillas costumbres; dejándonos en cambio sin fisonomía propia, y haciendo de nuestro modo de ser una especie de colcha de retazos de diferentes nacionalidades, como las de muestras de zaraza que cubren las camas de 
algunos pobres. En efecto, desde lo pequeño has lo grande, todo ha sido removido por la moda, y la muerte se ha encargado de destruir lo demás. (Silva, 1883, pp. 147-148)

Esta importante dinámica de cambio también aplicaba a temas relacionados con la normatividad y la moral de los negocios y la contabilidad, en la representación que a continuación se describe.

\section{Prueba de legalidad y honradez}

En el ya citado libro de Cuadros de costumbres (1883), Ricardo Silva Frade formulaba un texto en un tono muy satírico, sobre esta "penosa enfermedad social, incurable" (p. 115) denominada las juntas, es un hecho significativo que la básica unión de individuos en procura de diferentes objetivos, políticos, económicos, sociales, comunitarios, se tornará en los nuevos escenarios capitalistas en una curiosa pérdida de tiempo. Con detalle y en un lenguaje cargado de términos económicos afirmaba:

Junta, según el diccionario de nuestra lengua, es una reunión de personas para tratar un negocio. Esto será en España. Entre nosotros, es una reunión de personas que no se reúnen. (...) Tienen además las juntas otra ventaja de inestimable precio: el don de la inoportunidad que las caracteriza. Toda junta o tentativa de junta por suscripción para algo, y por nombramiento de una o de varias comisiones, y toda comisión de estas, termina sus trabajos antes de empezarlos. (p. 116)

El concepto de la junta se refiere a una manera moderna de gobierno de las organizaciones, novedosa en referencia a las tradicionales figuras de los mayordomos o los albaceas, que habitualmente llevaban sus cuentas por el esquema del cargo y data. Estas juntas, en su lugar, eran gestionadas por tres instancias administrativas: el presidente, el secretario y el contador o tesorero. Sobre los dineros controlados por estos últimos, que son los encargados de la contabilidad, se advertía que:

Son "tesoros de paciencia" para las víctimas que las manejan, y estas hacen, en lo general, de sus propios recursos, los gastos de instalación, como de libros, papel, esquelas, avisos, repartidores, \&c., lo cual tienen, entre otras, la grandísima ventaja de que el tesorero es irresponsable por dichos desembolsos. Tampoco hay necesidad de comprobar dichas cuentas, porque el bolsillo del tesorero las reconoce y acepta de antemano sin aquella formalidad. (p. 116)

A pesar del aire jocoso de la narración se aprecia la relevancia atribuida a las cuentas y el control de un tercero diferente al gestor de la organización. Es por esto que en la segunda mitad del siglo XIX, una buena contabilidad se tenía como un medio para valorar de manera rigurosa el patrimonio de los negocios y las familias, ya que no era costumbre hacer una diferenciación contundente entre estas dos instancias (Ariza, 2001; Cubides, 1991;). Además, era un insumo para establecer las perspectivas de diferentes riesgos y la necesidad de diversificarlos, por lo que, dado el contexto, era común que los 
Rico, C. La contabilidad en Colombia de la segunda mitad del siglo XIX...

comerciantes participaran de diferentes actividades, o especulaciones como solía denominársele, a medida que tenían la oportunidad de crecer en inversiones de corto plazo (Mejía, 2011; Molina, 1998; Ocampo, 1984; Pérez, 2008).

No llevar al día las cuentas era un parámetro que podía incidir de forma contundente en la quiebra de un negocio o, más ampliamente, en la extinción de una red familiar. Con una deficiente teneduría de libros, un comerciante era más vulnerable a sufrir pérdidas a raíz de la toma de decisiones financieras equivocadas. En este sentido, algunas investigaciones sobre historia empresarial del siglo XIX asocian la solvencia, el crecimiento y el éxito de las actividades mercantiles con el fino cuidado en el diligenciamiento y el análisis minucioso de los libros (Barragán, León y Torres, 2011; Molina, 1998; Pérez, 2008). El desorden y la confusión contable eran una "fuente inagotable de pleitos y de molestias al tratarse de una liquidación o de un arreglo cualquiera (...)" (Silva, 1879, pp.755-756).

Por tanto, en el periodo señalado, se reforzó la representación de la contabilidad, y particularmente de los libros como una prueba escrita; en otras palabras, un elemento documental con sustancia jurídica a partir del cual, en parte, se podría evidenciar la legalidad de las actuaciones del comerciante en el desarrollo de sus negocios y actividades, tanto en su favor como en su contra (Concha, 1893). De igual modo, su honradez a la hora de responder antes los diferentes terceros que habían depositado su confianza en él, a través de un fiado, una comisión, una cuenta en consignación o un crédito. En términos del mencionado Código de Comercio Neogranadino de 1853:

Los libros de comercio que tengan todas las formalidades que van prescritas, y no presenten vicio alguno legal, serán admitidos como medios de prueba en las contestaciones judiciales que ocurran entre asuntos mercantiles entre comerciantes. (...) También harán prueba los libros de comercio en favor de sus dueños cuando su adversario no presente asientos en contrario, hechos en libros arreglados a derecho, $\mathrm{u}$ otra prueba plena y concluyente. Finalmente, cuando resulte prueba contradictoria de los libros de las pares que litigan, y unos y otros se hallen con todas las formalidades necesarias, sin vicio alguno, el Tribunal prescindirá de este medio de prueba, y procederá por los méritos de las demás probanzas que se presenten. (Artículo 43)

Esta dimensión simbólica de la teneduría de libros y las cuentas se hacía más pronunciada y notable en escenarios donde la honradez y la buena fe de los comerciantes quedaban en entredicho; por ejemplo, los juicios de cuentas, las sucesiones y los concursos de acreedores, reuniones que, a pesar de estar reguladas por la ley, no gozaban de buena imagen en la cultura popular, como dice el verso: "Es por esto señor don Amadeo, que, ni en las juntas de acreedores creo" (Silva, 1883, p. 127).

Es sobre esta base que se fortaleció la interrelación entre las prácticas y las doctrinas de la contabilidad y el derecho, entendiendo a las primeras como 
un instrumento soporte de las últimas, en la que se acumulaban los vínculos contractuales con la administración estatal, los clientes, los prestamistas y los acreedores, a partir de las cuentas por cobrar y pagar, que usualmente se consignaban y controlaban en libros auxiliares. Como lo indicaba aún mucho tiempo después la doctrina jurídica colombiana:

Es principio inconcuso que en los libros de comercio sólo se abren cuentas a las personas con quien se tienen negocios a crédito o en cuenta corriente. Por consiguiente, toda cuenta personal abierta en los libros de un comerciante expresa una relación jurídica entre este y la persona a quien está abierta, y de ella ha de resultar cuál de los dos es acreedor y cuál deudor, y por qué causa. (Corte Suprema de Justicia, 1930, citado en González, 1958, pp. 23-24)

Estas líneas son muy cercanas a las escuelas de la personificación y el contismo, de origen continental europeo, que hacían énfasis en los aspectos formales y procedimentales de la práctica contable dejando de lado los asuntos materiales y sustanciales (Tua, 1988), y que fueron las doctrinas dominantes en el pensamiento contable y la enseñanza de la contabilidad en la Colombia del siglo XIX e, incluso, buena parte del XX (Cubides, 1991; Rico, 2018).

No obstante, el empleo de documentos contables como una prueba no fue un tema sencillo de implementar, en primer lugar, porque la legislación era bastante exigente en que se garantizara su calidad formal a fin de constituirse en un documento válido judicialmente. Los libros debían estar encuadernados, foliados y rubricados por un funcionario público para constituirse en una evidencia sólida en un proceso jurídico en el que se juzgara la buena fe de los actos de comercio y siempre que no se llegase a afectar el secreto mercantil al que tenían derecho los comerciantes, que eran el foco de la regulación empresarial de la época (Concha, 1893; Machado, 2006; Sierra, 2001).

Además, el escaso conocimiento de la contabilidad por parte de los jueces, los abogados y el público en general, limitaba su aplicación. Era preferible profundizar en el debate de los principios jurídicos abstractos, que en la revisión al detalle de los libros, la correspondencia y las cuentas. Esto sin contar con la evaluación y la posición doctrinal que adoptara cada una de las partes en conflicto en el alcance probatorio de esta documentación (Concha, 1893). Así lo advertía en una reflexión, en 1870, el reconocido abogado Juan Crisóstomo Campuzano (1870), en el marco de un juicio de cuentas asociado a un pleito familiar por la distribución de unas herencias:

Es muy sabido que en este país son recientes las ideas sobre la verdadera naturaleza de la contabilidad; y que, por lo mismo, los hombres que nacieron aquí a fines del siglo pasado, no solo ignoraban el sistema moderno de la partida doble, sino que carecían de todo método para llevar una cuenta de alguna extensión con la ordenada claridad del caso. Este era un mal de la época, y en consecuencia no debe extrañarse que cuanto les sobrara en buena fe les faltara en orden y precisión. (p. 25) 
Rico, C. La contabilidad en Colombia de la segunda mitad del siglo XIX...

En algunas ocasiones, con el objeto de validar la calidad formal y material de la contabilidad, de manera que se lograra constituir en una prueba legal y una muestra de honradez, los comerciantes recurrían a personas con alguna experticia en temas contables para que estas revisaran y dictaminaran sobre su veracidad. En la correspondencia de José Asunción Silva del año 1891, por ejemplo, se halló la siguiente solicitud al Banco de Bogotá:

Muy respetuosamente suplico a ustedes que se sirvan nombrar a una persona de la entera y absoluta confianza del Banco de Bogotá con el objeto de que previo un examen minucioso de la contabilidad, el archivo y la correspondencia de la casa R. Silva e Hijo, (...) rinda a ustedes un informe acerca de la situación y el manejo de esos negocios (...) y rectifique la parte numérica de las operaciones descritas. (1996, p. 50)

En una comunicación posterior se comentaba que la institución financiera delegó un tenedor de libros, que conceptuó, luego de una detallada revisión, que el manejo de la casa comercial y, particularmente, de los libros y las cuentas no fue inhábil, y por el contrario se mostraba diligente (Silva, 1996). A pesar de esto, los resultados eran negativos dadas las ya referidas condiciones del entorno y la deuda insostenible que, incluso algunos años antes de la muerte de Ricardo Silva Frade en 1887, limitaban la continuidad del negocio y vaticinaban su disolución definitiva; evento que ocurrió poco tiempo después, en 1892, no sin cuestionarse la buena fe de la administración ejecutada por el poeta (Santos, 1992; Vallejo, 1995).

En todo caso, a pesar de lo limitado que pudo haber sido el mercado de servicios contables de aquel entonces, lo descrito anteriormente es una muestra relevante del desarrollo de la confianza que la sociedad, y específicamente la legislación colombiana va a ir construyendo alrededor de la figura del contabilista, o en nuestros términos de hoy día, del contador público, y que se materializará posteriormente con la regulación de la profesión en la segunda mitad del siglo XX, fortaleciendo las representaciones de la contabilidad descritas en esta investigación.

\section{VI.Conclusiones}

En la segunda mitad del siglo XIX se identifican algunos aspectos socioeconómicos y políticos muy importantes para la caracterización de las prácticas y las ideas contables de esta época, como lo son el desarrollo de la industria privada del tabaco, que junto con el oro y el café fueron los principales productos de exportación del país en la citada centuria. De igual manera, los cambios en la regulación sobre el comercio, la contabilidad gubernamental y la constitución de sociedades anónimas; además, la difícil situación monetaria, de crédito y medios de pago, que afectó temas como la unidad de cuenta y la mínima expansión de los mercados de servicios, entre ellos, el contable. 
En este contexto de transición de mentalidades y principios coloniales a valores capitalistas, a partir de las fuentes primarias consultadas, se evidenció y profundizó en dos líneas de representación de la contabilidad: primero como una herramienta útil para la toma de decisiones, especialmente de tipo comercial, en el marco de una notable necesidad por diversificar riesgos de corto plazo, en múltiples actividades de especulación, con fuentes de financiación muy limitadas, que fácilmente terminaban en negocios con deudas deterioradas o en procesos de quiebra.

En segundo término, como una manera no solo de calcular el patrimonio, sino en complemento, un reflejo de las relaciones contractuales y jurídicas de las organizaciones económicas con terceros, que se podía constituir en un elemento probatorio de la legalidad de los actos de comercio y en evidencia de la honradez y buena fe de sus ejecutantes; tema que, si bien no fue de fácil aplicación, por limitaciones formales y de desconocimiento de la técnica contable, ayudó a fortalecer las bases jurídicas de la confianza social en el trabajo del futuro profesional contador público.

En este sentido es de resaltar, finalmente, la importancia de más investigaciones en historia de la contabilidad en Colombia, en las que se pueda explicar y comprender con detalle las prácticas contables que se adelantaron en el siglo XIX, en las unidades de producción de los mencionados bienes de exportación y otros como la quina, el banano y las esmeraldas y, claro, en el comercio de importación dominado por los textiles y los mercados locales de bienes primarios como la sal, la carne, la caña de azúcar y el maíz.

De la mano de esta perspectiva, a pesar de que el grado de elaboración de las cuentas y la teneduría de libros sea en muchos casos reducido, o, en otras palabras, que las fuentes primarias no sean numerosas o significativas, es relevante profundizar en el desenvolvimiento de las prácticas, el pensamiento, la regulación y la profesión contable con énfasis en las distintas áreas geopolíticas del país. Con este objetivo, se podrían buscar apoyos y vínculos con la historia económica y empresarial, y también con otras como la social y la cultural.

\section{Referencias bibiográfica}

Ancízar, M. (1853). Peregrinación del Alpha por las provincias del norte de la Nueva Granada, en 1850-1851. Bogotá: Imprenta de Echeverría Hermanos.

Ariza, D. (2001). El carácter de la empresa y la contabilidad en la Nueva Granada (Tesis de Maestría sin publicar). Universidad Nacional de Colombia, Bogotá.

Barragán, D., León, E. y Torres, F. (2011). Relaciones entre contabilidad y redes familiares en Colombia durante la segunda mitad del siglo XIX. Cuadernos de Contabilidad, 12(31), 585-599.

Beckman, E. (2009). Sujetos insolventes: José Asunción Silva y la economía transatlántica del lujo. Revista Iberoamericana, 75(228), 757-772. 
Rico, C. La contabilidad en Colombia de la segunda mitad del siglo XIX...

Campuzano, J. (1870). Primera respuesta a la demanda sobre cuentas, entablada por los señores Herman Juan de Dios y Alejandrina Suescún Gómez, contra la mortuoria del señor doctor José Joaquín Gómez Hoyos. Bogotá: Imprenta de Echeverría Hermanos.

Colmenares, G. (1968). Partidos políticos y clases sociales. Bogotá: Universidad de los Andes.

Concha, J. (1893). Elementos de pruebas judiciales extractadas de las obras de Bonnier y Mittermaier y anotados con las disposiciones vigentes sobre pruebas de las leyes colombianas. Bogotá: Librería Americana.

Cubides, C. (1991). Evolución de la capacitación y formación de los contadores públicos, en Historia de la contaduría pública en Colombia siglo XX: elementos para su interpretación (pp. 35-136). Bogotá: Ediciones Universidad Central.

Czarniawska, B. (2008). Accounting and gender across times and places: an excursion into fiction. Accounting, Organizations and Society, 33, 33-47.

Gómez, A. (1946). Historia de la literatura colombiana. Bogotá: Ministerio de Educación Nacional.

González, H. (1958). De los libros de comercio. Cali: Imprenta Departamental.

González, J. (2010). Desprofesionalización de la enseñanza y desarrollo del saber contable. Revista Activos, 14, 19-27.

Gordillo, A. (2003). El Mosaico (1858-1872): nacionalismo, élites y cultura en la segunda mitad del siglo XIX. Fronteras de la Historia, 8, 19-63.

Grajales, J.S. (2007). Prejuicios hacia la contaduría pública: una mirada a la realidad desde la ficción literaria. Contaduría Universidad de Antioquia, 51, 183-198.

Gutiérrez, R. (2000). Estratificación social, cultura y violencia en Colombia. Revista de Estudios Sociales, 7, 9-18.

Hernández, E. (2013). Aproximación al estudio del pensamiento contable español. Madrid: Asociación Española de Contabilidad y Administración de Empresas (AECA).

Kalmanovitz, S. y López, E. (2010). El ingreso colombiano en el siglo XIX, en A. Meisel y M. Ramírez (Eds.). Economía colombiana del siglo XIX (pp. 331-373). Bogotá: Banco de la República - Fondo de Cultura Económica.

Machado, M. (2006). Una aproximación histórica a las representaciones contables en Colombia. De Computis - Revista Española de Historia de la Contabilidad, 5, 166-192.

Machado, M. (2011). Representación contable: de la revelación de los hechos a la construcción de la realidad. Lúmina, 12, 152-171.

Marroquín, J.M. (1897). Entre primos. Bogotá: Imprenta de Eduardo Espinosa Guzmán.

Mattessich, R. (2000). Literature and insights. "Forensic" accounting in Spanish bellesletters of the nineteenth century. Accounting, Auditing and Accountability Journal, 13(5), 681-689.

Means, R. (2010). Desarrollo y subdesarrollo del derecho. Corporaciones y derecho corporativo en la Colombia del siglo XIX. Bogotá: Universidad Externado.

Mejía, R. (2011). El riesgo y la historia empresarial antioqueña. Medellín: Fondo Editorial Universidad EAFIT.

Molina, L. (1998). Empresarios colombianos del siglo XIX. Bogotá: Banco de la República - El Áncora Editores. 
Molina, L. (2003). Francisco Montoya Zapata: poder familiar, político y empresarial, 1810 1862. Medellín: Nutifinanzas.

Nueva Granada, Congreso Constitucional. (1853). Ley 2193 de 1853, 1 de junio, Código de Comercio.

Ocampo, J. (1984). Colombia y la economía mundial, 1830 -1910. Bogotá: Tercer Mundo Editores.

Ocampo, J. (1994). Regímenes monetarios variables en una economía preindustrial: Colombia, 1850-1933, en F. Sánchez (Ed.). Ensayos de historia monetaria y bancaria de Colombia (pp. 305-329): Bogotá: Tercer Mundo Editores.

Palacio, M. (1979). El café en Colombia (1850 - 1970). Una historia económica, social y política. Bogotá: Editorial Presencia - Fedesarrollo.

Pérez, J. (2008). Contabilidad creativa: desde José Asunción Silva hasta nuestros días. Revista Internacional Legis de Contabilidad y Auditoría, 34, 73-98.

Pombo, J. (1888). Directorio general de Bogotá: año II. Bogotá: Imprenta de la Luz.

Quijano, J. (1908). Estudios, discursos y escritos varios. París: R. Roger y F. Chernoviz Editores.

Rico, C. (2012). Historia de la contabilidad bancaria en Colombia: el caso del Banco Nacional (1880-1896). Revista Internacional Legis de Contabilidad y Auditoría, 51, 101-137.

Rico, C. (2015). Antecedentes de la disciplina contable en la Universidad Nacional de Colombia: El curso de los profesores Víctor Touzet y Ángel María Galán (1868 - 1882), en Z. Melgarejo (Ed.). Contribuciones al desarrollo disciplinar de la contabilidad (pp. 73111): Bogotá: Universidad Nacional de Colombia.

Rico, C. (2016). Historia de la regulación contable financiera en Colombia: el caso de la industria ferroviaria (1870 - 1920). Cuadernos de Contabilidad, 17(43), 43-72. http:// dx.doi.org/10.11144/Javeriana.cc17-43.hrcf

Rico, C. (2018). Análisis histórico del pensamiento contable colombiano: tratados, libros de texto y lecciones de enseñanza $(1840$ - 1950). De Computis - Revista Española de Historia de la Contabilidad, 15(1), 26-50. http://dx.doi.org/10.26784/issn.1886-1881. v15i1.324.

Salgado, C. (1893). Directorio general de Bogotá: año IV. Bogotá: s.d.

Santos, E. (1992). El corazón del poeta. Bogotá: Nuevo Rumbo Editores.

Sierra, E. (2001). Evolución de la normativa contable en Colombia. Innovar, 17, 47-65.

Silva, José Asunción. (1996). Cartas: 1881-1896. Bogotá: Ediciones Casa Silva.

Silva, R. (1879). Un libro útil. El Zipa - Periódico Literario, 48, 755 - 756.

Silva, R. (1883). Artículos de costumbres. Bogotá: Imprenta de Silvestre y Cía.

Tua, J. (1998). Evolución del concepto de contabilidad a través de sus definiciones. Contaduría Universidad de Antioquia, 13, 9-74.

Vallejo, F. (1995). Chapolas negras. Bogotá: Alfaguara.

Williams, R. (1991). Novela y poder en Colombia. Bogotá: Tercer Mundo Editores. 
Rico, C. La contabilidad en Colombia de la segunda mitad del siglo XIX...

Anexo 1. Publicidad del negocio de Ricardo Silva Frade y su hijo, el poeta José Asunción Silva.

\section{R. SMIYA E MIJO.}

291 y 293, Carrera 7. ", segmilla Calle Real. (Jintol al i t templo dle santo Domingo).

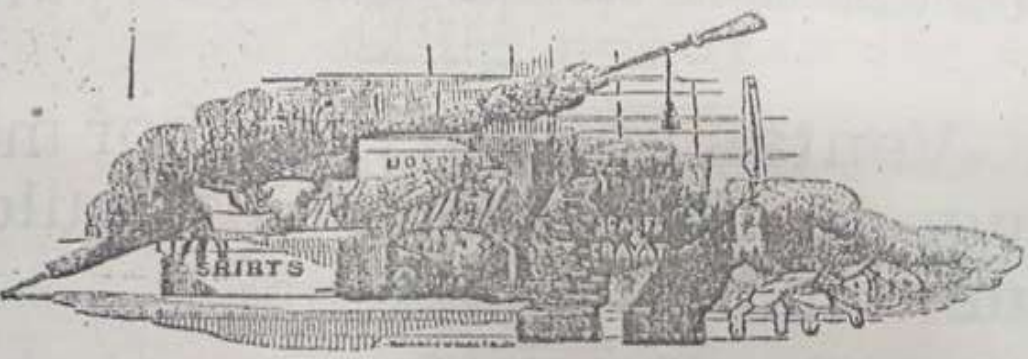

Surticlo de mercancías firancesas, renovado mensualmente.

Ventas al contado. Precios modicos.

Papel de colgadura.

Paños finos.

Ropa blanca y calzado para señora. Telas de lana. Objetos para regalo. Pianos.

Fuente: (Pombo, 1888, s.p). Documento de acceso público. 
Anexo 2. Cuadro de costumbres de Ricardo Silva

\section{ESTILO DEL SIGLO}

\section{FANTASIA EN ESTILO COMERCIAL, DEDICADA A}

JOAQUIN SUAREZ FORTOUL

SEÑORITA SARA AZA — Presente.

Bogotá, enero 25 de 1860.

ESTIMADA SEÑORITA - sin ninguna de usted a que contestar, tiene esta mi única por objeto, avisarle que, desde esta fecha en adelante quedan disueltas las relaciones que me han ligado a usted en un año, tres meses, cinco días, contados desde aquél en que tuve conocimiento de usted hasta hoy. El notable cambio que en usted noto hace algún tiempo, o mejor dicho, la paralización completa del interés que usted antes me manifestaba, me habían hecho comprender ya, que usted no quería tener cuentas de ninguna especie conmigo, a pesar de la obligación que contrajo de no faltar nunca a los compromisos que estipulamos cuando yo abrí el inmenso libro de mi alma ante los ojos de usted; así es que si yo había guardado silencio en este negocio, era únicamente porque había resuelto darme un plazo para estudiar bien a fondo esta cuestión. Al efecto, abrí desde entonces un diario en el cual he venido cargando todas las malas partidas de usted, hasta ayer, fecha en que, gracias a la franqueza de usted, no me quedó duda sobre la exactitud de mis observaciones.

Graves son, señorita, los daños y perjuicios que usted me ha causado, ya por el engaño de que me ha hecho víctima, como por su demora en manifestarme los sentimientos que realmente abrigaba, y que de algún tiempo a esta parte ha tomado usted como guía de sus acciones para conmigo.

No ignora usted que, si yo hubiera dirigido mis propuestas a otra parte, habrían sido aceptadas y que tal vez hubiera podido colocarme con algunas ventajas; cosa que hoy, por mi desgracia, se hace imposible, pues aun cuando los hombres como yo, son artículos escasos en el mercado amoroso, y la abundancia de mujeres se hace sentir, es seguro que ya ninguna querrá, admitirme, ni aun de contado o a la vista, por tener el carácter de endosado. Sin embargo, como yo debo a usted la pequeña utilidad de no volver a experimentar la crisis que hoy sufro, no hago a usted reclamaciones de ninguna clase. 
Rico, C. La contabilidad en Colombia de la segunda mitad del siglo XIX...

Mi corazón se encuentra completamente averiado con este fracaso; yo me estoy muerganizando a la carrera, y no tengo probabilidad de ser indemnizado; pero acepto está perdida, y poniendo al cielo por testigo, se la ofrezco a Dios en descuento de mis culpas y pecados.

Adjunto a usted la facturita y cuenta de los chismes que como comprobantes de su afecto me dio; siendo de cargo de usted revisarla y avisarme si estamos o no de conformidad, pues quiero arreglar cualquier saldo que resulte para dejar así canceladas nuestras cuentas.

\section{LA SEÑORITA SARA AZA}

Su cuenta corriente con

\section{MÁRTIR PLAZA DE MERCADO}

1859.

Debe. Haber.

Enero 21—Un pañuelito imitación de olán, bordado, que me dio en el teatro.

Cosas..............................................................................., ,

Febrero 4-Un ramo de flores artificiales; 5 flores y dos botones, en todo, cosas

Agosto 20-Un bouquet atado con un lazo de cinta,

cosas.................................................................................

Agosto 23-Un guante faltándole 2 dedos, o sean dedos

cosas..........................................................................................

Septiembre 14-Una rosca de pelo engomado, roscas ............................., , , 1---

Id. 20-Un anillo triple dorado con esta

inscripción "Souvenir"

$1--$

Noviembre $1^{\circ}$ —Una bufanda, fantasía a cuadros, 1860.

hoy día de mi santo.............................................................., , , 1 --

Enero 25-Existencia de cartas, según inventario de hoy ......................., , 43---

Id. 25-Igual número de cosas que le remito y por saldo................ $\underline{59 \ldots \ldots}$

S: E ú O.—Total cosas id.................................................... 59... 59-.

Ahora sólo me falta suplicar a usted, señorita, que se sirva disimular las molestias que la he causado. iiQuiera el cielo que el bajel a cuyo bordo se ha embarcado usted, no vaya a naufragar antes de arribar al puerto de la felicidad!!...Siempre sería bueno que usted se asegurara antes. En fin, como no me es dado aconsejarla, corto aquí está mi carta, repitiéndome de usted, muy atento seguro servidor, Q. B. S. M.

Mártir Plaza de Mercado y Plata.

22 de diciembre de 1860 .

Fuente: (Silva, 1883, pp. 35-37). Documento de acceso público.

Nota: Las letras cursivas son propias del original. 